\title{
Práticas científicas e difusão do conhecimento sobre eletricidade no século XVIII e início do XIX: possibilidades para uma abordagem histórica da pilha de volta na educação básica
}

Scientific practices and spreading of knowledge on electricity in the eighteenth and early nineteenth centuries: possibilities for a historical approach of the voltaic pile in basic education

\author{
Wagner Tadeu Jardim¹@, Andreia Guerra²
}

\author{
${ }^{1}$ Instituto Federal de Educação, Ciência e Tecnologia do Sudeste de Minas Gerais, Juiz de Fora, MG, Brasil \\ ${ }^{2}$ Centro Federal de Educação Tecnológica Celso Suckow da Fonseca, Rio de Janeiro, RJ, Brasil
}

Recebido em 29 de Outubro, 2017. Revisado em 23 de Fevereiro, 2018. Aceito em 17 de Março, 2018.

\begin{abstract}
Neste artigo, discutiremos o panorama, que permeia a construção da primeira bateria elétrica, conhecida como a pilha de Volta. A partir de uma visão pautada na vertente historiográfica da História Cultural da Ciência, construímos uma narrativa histórica nos apoiando em fontes primárias e secundárias. Buscamos ressaltar, no século XVIII e início do século XIX, a controvérsia acerca da natureza do fluido animal, a utilização da eletricidade com finalidades medicinais e os aparatos elétricos que emergem nesse período, destacando que a teoria e a prática científica tecem um diálogo complexo de saberes. Salientamos questões inerentes ao contexto sociocultural e às práticas extra-laboratoriais indispensáveis para a construção e estabelecimento do conhecimento científico, tais como os caminhos de difusão e popularização do conhecimento no referido contexto. Ao final, discutimos como o episódio que envolve a construção da pilha de Volta fomenta discussões relevantes sobre a complexidade da construção do conhecimento científico que se mostram de grande potencial para o trabalho em aulas de ciências e em aulas de Física, em especial.

Palavras-chave: História Cultural da Ciência, Experimentos históricos, Pilha de Volta, Controvérsia GalvaniVolta, Ensino de Física.
\end{abstract}

In this paper, the panorama that underpin the construction of the first electric battery, known as the Voltaic pile, will be presented. For this purpose, an historical narrative was constructed from primary and secondary sources, and was inspired by the historiographical strand called Cultural History of Science. Taking the eighteenth and early nineteenth century, we sought to highlight the controversial aspects over the nature of animal fluid, the use of electricity for medicinal purposes and the electrical apparatus that emerged during this period, emphasizing that scientific theory and scientific practices weaves a complex relationship about the construction of knowledge. Thus, we seek show how socio-cultural context and the extra-laboratory practices were indispensable for the construction and establishment of scientific knowledge, such as the ways of spreading and popularizing knowledge in that context. Finally, we present some thoughts upon how the episode involving the construction of the Voltaic pile fosters relevant discussions about the complexity of the construction of scientific knowledge that shows great potential for work in science classes and, more especificaly, in physics classes.

Keywords: Cultural History of Science, Historical Experiments, Voltaic Pile, Galvani-Volta controversy, Physics Teaching.

\section{Introdução}

Um ensino de ciências a partir de uma abordagem históricofilosófica-sociológica da ciência é apontado por vários estudiosos como uma possibilidade para trazer discussões sobre as ciências para as salas de aula [1-3]. Nessa perspectiva, o trabalho com experimentos históricos se apresenta como importante, uma vez que os trabalhos empíricos muitas vezes são referenciados na História da

*Endereço de correspondência: jardimwt@gmail.com
Ciência como argumentos fundamentais para a resolução de controvérsias, validação ou refutação de teorias $[4,5,6]$.

Apesar da grande relevância designada à atividade experimental, questões inerentes ao contexto sociocultural e às práticas extra-laboratoriais são fundamentais para se compreender o desenvolvimento das atividades experimentais. Porém essas são questões muitas vezes negligenciadas na História da Ciência [4]. Essas considerações nos levaram à construção de uma revisão bibliográfica das pesquisas que destacam o trabalho com experimentos 
históricos no ensino, com vistas a compreender como o tema está sendo discutido na área [6]. Essa revisão bibliográfica indicou que os trabalhos com experimentos históricos no ensino, desenvolvidos em âmbitos nacional e internacional, pautados ou não na replicação de um aparato experimental, de maneira geral, se destinam a discutir aspectos como a materialidade envolvida na construção do experimento, as técnicas diretamente empregadas na execução do mesmo e a coleta dos dados e às interpretações construídas como respostas às hipóteses iniciais.

Apesar da importância da materialidade em torno à construção dos experimentos, alguns historiadores da ciência [4,7-11], ao explorarem a experimentação no processo de construção das ciências não se atêm a questões relativas à cultura material. Eles discutem os experimentos e as atividades experimentais, situando as práticas ali estabelecidas em seu contexto sociocultural. Assim, são reconhecidos os diferentes agentes sociais envolvidos no processo, como os técnicos e auxiliares de laboratório [9], os instrumentadores e palestrantes [10] e os camponeses e os nativos que reportaram aos acadêmicos achados julgados de grande valor científico [11]. A organização das formas de validação e difusão do conhecimento produzido também desempenha um importante papel nas práticas experimentais, sobre o qual podemos citar as academias e sociedades científicas no século XVIII, além dos meios impressos ou não de circulação do saber produzido [1114]. Dessa forma, busca-se com esse enfoque histórico não ressaltar unicamente os grandes centros de produção científica, os grandes nomes e feitos isolados [7].

Assim, fomos levados à construção de uma pesquisa que subsidiou a elaboração do presente artigo e que teve por objetivo discutir quais questões relativas às ciências podem ser elencadas em aulas de Física, a partir de estudos sobre experimentos históricos na abordagem ressaltada. Com o propósito de delimitar o objeto de pesquisa, nos dedicamos ao estudo de aspectos relacionados à eletricidade no século XVIII e início do XIX, com vistas a discutir o caso específico da pilha de Volta em seu contexto sociocultural. Pretende-se, assim, que esse trabalho traga subsídios para a construção de intervenções pedagógicas em aulas de ciências, e, em especial, em aulas de Física que tenham a preocupação de discutir não apenas os conteúdos científicos, mas, também, o processo de construção das ciências.

A escolha do recorte histórico se deu devido a vários fatores. Em primeiro lugar deve-se destacar que o tema eletricidade é comumente trabalhado na educação básica e a pilha voltaica teve um papel preponderante no desenvolvimento da eletricidade no início do século XIX. A construção da pilha esteve ligada a diferentes áreas como a física, a química e a fisiologia animal, porém como salientam Germano, Lima e Silva [15] seu estudo é trabalhado com atenção na educação básica apenas nos cursos de química [15]. Apesar disso, defende-se que discutir o episódio histórico que circunda a pilha de Volta em aulas de Física permite explorar fenômenos eletrostáticos e de corrente elétrica, que podem servir de ponto de partida para o estudo de eletricidade nessa disciplina $[15,16]$.

Em termos acadêmicos, a temática da eletricidade tem atenção na literatura da área do ensino de Física. Discussões acerca de conteúdos voltados para o estudo da eletricidade aparecem na literatura a partir de análises críticas de como a perspectiva histórica a respeito da temática é trabalhada em livros didáticos e paradidáticos [17], e em trabalhos que visam construir subsídios para um ensino a partir da perspectiva histórica [18]. Além dos aspectos históricos, se destaca como relevante para o ensino de física, o enfoque experimental sobre a temática [19], seja qualitativo ou quantitativo [20, 21]. Nesse sentido, aliando discussões históricas à experimentação, encontramos na literatura nacional, propostas de construção de pilhas voltaicas, que podem ser facilmente implementadas nas salas de aula [15] e, nesses casos as discussões a serem estabelecidas nesse trabalho podem agregar questões importantes ao estudo da temática.

Ainda considerando a justificativa do recorte histórico estabelecido, deve-se pontuar que Volta construiu a pilha imerso em um contexto sociocultural em que os estudos sobre a eletricidade se mostravam de grande interesse e considerava-se necessário compreender a natureza do fluido elétrico em diversos fenômenos elétricos, como os manifestados na atmosfera, no corpo dos animais ou em um raio. Essa discussão acerca da natureza do fluido elétrico engloba a controvérsia entre Alessandro Volta (1745-1827) e Luigi Galvani (1737-1798). Galvani, investigando contrações musculares em rãs que eram postas em contato com metais, interpretou o fenômeno como sendo causado por um fluido invisível, chamado de "eletricidade animal". Por outro lado, Volta creditou os fenômenos observáveis à eletricidade ordinária, que seria produzida pelo contato entre diferentes metais, o princípio básico da pilha de Volta [16].

A pilha, artefato construído em 1800, foi rapidamente difundida, o que levou à sua popularização e apropriação por acadêmicos e não-acadêmicos, principalmente em questões relacionadas ao uso do artefato na eletrólise da água. Essas e outras questões concernentes à construção e divulgação do aparato constituem elementos extra-laboratoriais importantes para um entendimento do processo de construção da ciência, de forma a destacar as ciências enquanto produções culturais.

Vale ainda ressaltar que poderíamos construir o estudo pretendido focando exclusivamente na controvérsia Galvani e Volta, no entanto, entendemos que referenciar apenas esses dois personagens configura uma simplificação demasiada do episódio. Ressaltamos, então, que apesar de receberem um maior destaque na narrativa que apresentaremos, se tornou relevante situar a controvérsia Galvani versus Volta em um contexto que é antecedido por estudos de fisiologia e da aplicação da eletricidade em estudos médicos e de fisiologia animal, discussões essas que, mesmo após o estabelecimento do aparato, 
não encontra seu fim imediato. Nesse panorama, diversos atores se destacam. Dessa maneira, julgamos importante enfatizar a contribuição de diferentes personagens na discussão histórica a ser apresentada. Sem podermos deter em cada um deles com a merecida atenção ou negligenciar suas participações no episódio histórico selecionado, procuramos contextualizar os personagens destacados, ressaltando a relação existente entre uma grande gama de fatores presentes no contexto sociocultural da construção da pilha, tais como as relações de complexidade entre teoria e experimento na construção do conhecimento científico, os processos de difusão do conhecimento científico e a circulação e apropriação deste conhecimento pelos pares.

Com vistas a cumprir o objetivo do presente trabalho, após a discussão do episódio histórico propriamente dito, apontamos reflexões acerca do potencial da abordagem histórica apresentada para o Ensino de Física e quais os aspectos inerentes às práticas científicas envolvidas nesse episódio histórico podem contribuir para uma abordagem histórica, que além de apresentar o conteúdo científico tratado, possibilite discussões da ciência enquanto produção cultural de homens e mulheres imersos em um tempo e espaço específico.

\section{Eletricidade medicinal no século XVIII: instrumentando o saber e saber instrumentado}

Sobre o processo conhecido como Iluminismo, no que tange à ciência, apesar de encontrarmos na literatura, tentativas de defini-lo de forma simplificada, como sendo uma forma de construir conhecimento e um modo de vida que pressupõe a exclusão da metafísica e a utilização exclusiva de uma razão científica, nenhuma definição sucinta é capaz de abarcar toda a complexidade de práticas e pensamentos que compõem a construção do saber científico nesse período.

Diante da complexidade ressaltada, historiadores das ciências $[22,23]$ destacam que diversos fatores, constituintes das práticas científicas, se mostram essenciais para uma compreensão ampla das ciências e dos princípios que emergem sobre os alicerces do Iluminismo europeu e dos que com ele dialogaram. A construção de instrumentos científicos junto à difusão e adoção cada vez maior da prática experimental nas Universidades, nas palestras itinerantes, nas aulas particulares e nas demonstrações públicas constituíram parte da complexa cultura científica iluminista do século XVIII $[10,22,24]$. Para cada dezena de acadêmicos renomados, existiam centenas de outros praticantes da ciência fora das academias. Esses "não acadêmicos" produziram conhecimento científico e realizaram demonstrações ao público interessado [10,25].

No século XVIII, as palestras itinerantes sobre a filosofia natural, que eram pautadas na experimentação e tratavam de temas como, mecânica, eletricidade e anatomia alcançaram um grande público. Esse público era bem diverso, pessoas de diferentes classes sociais e formação participavam desses eventos. O público, composto de filósofos, senhoras, médicos, artesãos, membros do clero, dentre outros, não se limitava a uma atitude passiva, muitos, estimulados pelo que assistiam, se dedicavam à construção de novos instrumentos e à reaplicação de experimentos. Isso contribuiu para o olhar diferenciado sobre o material divulgado e estudado, tornando os estudos e argumentos apresentados ainda mais interessantes para um público que se tornava cada vez maior [25].

Além de contribuir para ampliar a produção científica, essas palestras itinerantes foram responsáveis por trazer reconhecimento para muitos filósofos naturais que estavam fora das academias [10,24-27]. Dentre os assuntos de maior interesse científico para o grande público se encontravam os estudos de anatomia e eletricidade $[10,28]$. Demonstrações acerca da eletricidade contavam, em meados do século XVIII, com diversos novos aparatos, como as máquinas eletrostáticas e os condensadores de carga ${ }^{1}[26,29]$.

Em relação às atividades práticas relacionadas à utilização da eletricidade na medicina, um termo foi cunhado no século XVIII: "eletricidade medicinal" (medical electricity). Eletricidade medicinal referia-se à "aplicação" do fluido elétrico no corpo humano com a intenção de que o mesmo agisse como terapêutico [30,31]. A partir de 1744, eletricistas alemães começaram a discutir as possibilidades de as descargas elétricas produzidas pelas máquinas elétricas poderem ser utilizadas na cura de doenças. Experimentos que envolviam pessoas e máquinas elétricas foram amplamente difundidos nas palestras itinerantes $[28,31]$. Dentre esses experimentos, alguns eram lúdicos, servindo principalmente ao entretenimento, como é o caso do denominado "beijo elétrico", criado por Georg Matthias Bose (1710-1761), professor na Universidade de Wittenberg (Alemanha), conhecido pela invenção de engenhosos procedimentos para suas demonstrações. Para a realização desse experimento, uma mulher disposta sobre uma plataforma de forma a permanecer isolada eletricamente tinha seu corpo carregado eletricamente por uma máquina elétrica. Após essa etapa, um homem da plateia era convidado a beijá-la na boca. Quando o mesmo se aproximava dos lábios da mulher, uma forte faísca lhe acertava. Apesar de servir para entretenimento, experimentos como esse podiam gerar novas questões científicas. Por exemplo, Johann Gottlob Krüger (1715-1759), professor de medicina e filosofia em Halle, na Alemanha, relatou em 1744 que todas as pessoas que participaram do experimento do "beijo elétrico" apresentaram pon-

\footnotetext{
${ }^{1}$ Nesse contexto, aos condensadores elétricos, nos referimos aqui às garrafas de Leiden, aparato construído pela primeira vez em 1745 [24]. A Garrafa de Leiden é um recipiente isolante que possui a superfície interna e externa revestidas por um material condutor elétrico, na época de sua construção, considerado capaz de armazenar fluido elétrico. Em termos modernos, seria um capacitor que permite armazenar excesso de cargas positivas em uma de suas superfícies e negativas na outra. Já as máquinas eletrostáticas, eram dispositivos mecânicos que geravam acúmulo de cargas elétricas a partir do atrito entre suas partes.
} 
tos vermelhos em suas mãos que só desapareciam após algumas horas. Além disso, ele observou que a eletrificação produzia movimento muscular involuntário e, junto com seu discípulo Christian Gottlieb Kratzenstein (17231795), divulgou que essas observações indicavam que a eletricidade poderia ser utilizada em tratamentos médicos relacionados a paralisias musculares [31].

As conclusões de Krüger e Kratzenstein foram rapidamente difundidas, levando Bose a construir vários outros experimentos nos anos de 1744 e 1745, para avaliar os efeitos da eletricidade sobre a respiração, circulação sanguínea, transpiração e pulso. Os tratamentos com eletricidade que começaram a ser administrados por Kratzenstein, nessa época, se tornaram muito conhecidos e foram replicados na Europa nas cidades de Copenhague, Viena, Uppsala, Estocolmo, Rouen e Lipsia. Nesse contexto, surgiram relatos de casos de curas de enfermidades a partir da utilização da "eletricidade medicinal". Esses relatos eram publicados em revistas de circulação popular e apareciam em maior número nesses veículos do que nos destinados a publicações acadêmicas [31].

Esse tipo de prática, a princípio, não recebia atenção dos acadêmicos e não era explorada pelos médicos em geral. Com o aumento do número de relatos que remetiam a benefícios alcançados pelo uso da eletricidade no corpo humano, a prática começou a atrair mais os acadêmicos. Em uma carta ao presidente da Royal Society, o naturalista inglês Henry Baker (1698-1774) argumenta que este é um assunto que merece atenção e descreve diversos relatos de tratamentos bem sucedidos a partir da administração da "eletricidade medicinal". Assim, Baker insistia que o tema não fosse negligenciado pelos estudiosos, pois os estudos trariam benefícios para as investigações filosóficas da época e para os possíveis efeitos terapêuticos da eletricidade [32]. No entanto, o crescente número de relatos favoráveis à prática e seu acolhimento por alguns acadêmicos não foram suficientes para uma aceitação uníssona da "eletricidade medicinal" e a questão se tornou uma controvérsia. Como contraponto à aceitação dessa prática, ressaltamos Jean-Antoine Nollet (1700-1770), renomado membro da Academia Real de Ciências de Paris e uma das maiores autoridades em eletricidade na época, que em colaboração com o médico Sauveur François Morand (1697-1773) e o cirurgião Joseph Marie François de la Sône (1717-1788), conduziu sistematicamente diversos procedimentos a partir da prática da "eletricidade medicinal" a um grupo de soldados paralíticos no Hôpital dês Invalides. Nollet defendeu que os procedimentos que ministrou trouxeram resultados "tão incertos que nem mesmo valeriam a pena ser mencionados" [31, p.27\%2].

$\mathrm{Na}$ Inglaterra, a partir das décadas de 1750 e 1760, a ampla divulgação da garrafa de Leiden, devido a sua simples reprodução, fácil manuseio e possibilidade de ser transportada sem transtornos, foi acompanhada de

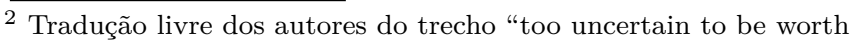
mentioning."
}

grande popularização da prática da "eletricidade medicinal". O maior problema no uso de uma garrafa de Leiden era o fato de a mesma necessitar de uma máquina eletrostática que lhe fornecesse eletricidade, todavia, essas máquinas não precisavam pertencer ao proprietário das garrafas, muitas vezes, as máquinas eletrostáticas eram compartilhadas por várias pessoas da mesma vizinhança [30].

O tema "eletricidade medicinal" foi destacado pelo inglês Joseph Priestley (1733-1804) em seu livro The History and Present State of Electricity with Original Experiments. Na secção destinada ao assunto, Priestley comenta diversos relatos de pesquisadores acerca da aplicação da eletricidade em seres humanos [33].

O assunto eletricidade medicinal recai quase totalmente sobre o período em que agora estou tratando. Apesar de alguns efeitos da eletricidade sobre os corpos de animais já terem sido observados por Abbé Nollet e, algumas pessoas doentes já terem relatado o recebimento do benefício de ser eletrificado, muito pouco havia sido feito sobre isso, e os médicos não haviam despendido a devida atenção, até então, quando a eletricidade se tornou um considerável artigo na materia medica [33, p. $472]^{3}$

Dentre os trabalhos descritos por Priestley, encontramos uma carta do britânico Willian Watson (1715-1787), membro da Royal Society, publicada na Philosophical Transactions que discorre sobre o sucesso do tratamento com eletricidade, entre novembro de 1762 e janeiro de 1763, em uma menina de aproximadamente sete anos, que antes do tratamento apresentava rigidez muscular [34]. Outro acontecimento destacado se refere a uma carta do estadunidense Benjamin Franklin (1706-1790) a seu amigo especialista em medicina militar e cuidados hospitalares, John Pringle (1707-1782), também publicada na Philosophical Transactions, na qual Franklin informa que, a partir da publicação de relatos de curas na Alemanha e Itália, diversas pessoas começaram a procurá-lo requisitando o tratamento com eletricidade. Assim, seguindo tais requisições, ele afirma que realizou procedimentos, nos quais administrava choques elétricos, três vezes por dia, em membros afetados das pessoas que buscavam tratamento, por meio de descargas elétricas oriundas de uma garrafa de Leiden. Todavia, Franklin afirma nesta carta que não observou nenhum benefício em administrar choques elétricos em pessoas que necessitavam trata-

\footnotetext{
3 Tradução livre dos autores do trecho "The subject of medical eletricity falls almost wholly within the período of which I am now treating. For though some effects of electricity upon animal bodies had been noted by Abbé Nollet, and a few diseased persons had Said thye had received benefit from being electrified; yet very little had been done this way, and physicians had scarcely attended to it, till within this período; whereas electricity is now become a considerable article in the materia medica".
} 
mentos medicinais, mas que "talvez alguma vantagem permanente pudesse ter sido obtida se os choques elétricos fossem acompanhados de remédios apropriados e alimentação controlada sob os cuidados de um médico habilidoso" [35, p.482 $]^{4}$

Joseph Priestley [33] destacou que um dos grandes empecilhos na prática medicinal com eletricidade era a dificuldade na aquisição e manipulação dos aparatos elétricos existentes até então. Em sua argumentação, ele chamou atenção para o trabalho de John Read. O matemático e instrumentador inglês John Read desenvolveu um aparato, cujo arranjo prático facilitava as operações de carga e descarga de garrafas de Leiden [33] e era passível de ser desmontado e armazenado de forma compacta. Além disso, esse aparato apresentava preços acessíveis, possibilitando sua popularização [30,31]. Read relacionou eletricidade à saúde, alegando que a eletricidade seria encontrada na terra e no vento e que a presença da mesma na atmosfera era benéfica para plantas e animais. Ele desenvolveu métodos para medir a eletricidade do ar na escola e no hospital de Knightsbridge e se utilizou dos resultados para reforçar sua tese de que o ar carregado de eletricidade era o ar saudável [36]. Um outro experimento realizado pelos franceses Nollet e Pierre-Nicolas Bertholon (1741-1800) corroborava a tese de Read. Nesse experimento, Nollet e Bertholon concluíram que vegetais se desenvolviam melhor em ambientes cuja atmosfera possuísse maiores concentrações de eletricidade. Importante aqui destacar, no entanto, que existia um problema relacionado à prática com a "eletricidade medicinal" que era a dificuldade em se dosar o fluido a ser utilizado [30], sendo assim, tornava-se importante o desenvolvimento de instrumentos capazes de controlar a intensidade dos choques elétricos.

Em 1766, o boticário de Londres, Dr. Timothy Lane (1733/4-1807), construiu um eletrômetro de descarga, aparato que segundo ele, poderia determinar com a precisão necessária a quantidade de fluido elétrico utilizada em um experimento. Em 1767, em uma carta a Benjamin Franklin, Lane descreveu a estrutura e funcionamento do eletrômetro construído (fig. 1) [37].

Priestley destacou a importância do aparato de Timothy Lane para administrar vários choques elétricos com iguais intensidades [33]. Apesar de Lane não se dispor a discutir eletricidade médica, ele trabalhou bem próximo a Willian Watson que, em 1770, o indicou como candidato a membro da Royal Society e apoiou sua candidatura. Lane foi apoiado também por Franklin e pelo inglês Henry Cavendish (1731-1810) [30].

No contexto da segunda metade do século XVIII, eletricistas com as mais diversas formações se dedicaram a questões da natureza da eletricidade e seu papel em diferentes situações. Nesse contexto, uma das questões

\footnotetext{
4 Tradução livre dos autores do trecho "Perhaps some permanent advantage might have been obtained, if the electric shocks had been accompanied with proper medicine and regimen under the direction of a skilful physician." [23, p.482]
}

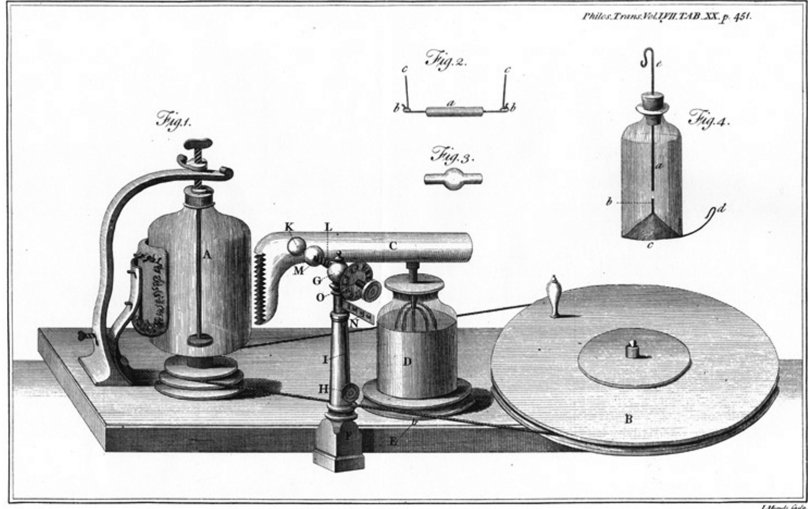

Figura 1: Montagem Experimental proposta por Dr. Tymothy Lane (1767) composta pela máquina elétrica de John Read, seu eletrômetro e uma Garrafa de Leiden De forma resumida, o eletrômetro consistia de duas esferas de latão, estando uma em contato com o gerador elétrico de John Read, a outra em contato com a superfície externa da garrafa de Leiden e um sistema que regularia, com grande precisão, a distância entre essas duas esferas. A quantidade de fluido elétrico armazenado pela garrafa era proporcional à distância entre essas esferas. Ilustração feita por J. Mynde. em Lane [37]

que se colocava referia-se à diferenciação entre a eletricidade obtida pelas máquinas eletrostáticas, eletricidade ordinária, e as provindas de relâmpagos e presentes na atmosfera, a chamada eletricidade atmosférica. Outra questão referia-se à tese de que haveria uma eletricidade animal, uma eletricidade que era própria dos corpos vivos. Evidências experimentais que apoiavam a tese de que a eletricidade ordinária e a eletricidade atmosférica deveriam ser iguais, apontavam a eletricidade como uma força da natureza que exerceria o poder sobre a vida e a morte [30].

Décadas após o advento da Garrafa de Leiden, e poucos anos após Lane construir um eletrômetro, outro instrumento se destacou no contexto da "eletricidade medicinal": o eletróforo $[38,39]$. O eletróforo é uma espécie de condensador, que é capaz de se manter eletrizado por longos períodos de tempo. Esse era um aparato de fácil manipulação e permitia eletrizar outros corpos, tais como garrafas de Leiden.

O primeiro eletróforo (fig.2) é atribuído a Alessandro Volta (1745-1827) no ano de 1775, quando descreveu seu eletroforo perpetuo (eletróforo perpétuo) em uma carta a Priestley [41]. Os princípios físicos que deram origem ao aparato foram discutidos nos anos anteriores por outros pesquisadores, estudiosos da eletricidade. O alemão Franz Ulrich Theodor Aepinus (1724-1802), em meados da década de 1750, descreveu efeitos físicos semelhantes ao do eletróforo, a partir de demonstrações experimentais realizadas por jesuítas. Tomando conhecimento desses estudos iniciais, os italianos Giambatista Beccaria (17161781) e Gianfrancesco Cigna (1734-1790) e o sueco Johan Carl Wilcke (1732-1796), dentre outros, desenvolveram diversos estudos relacionados ao tema e que viriam a tra- 


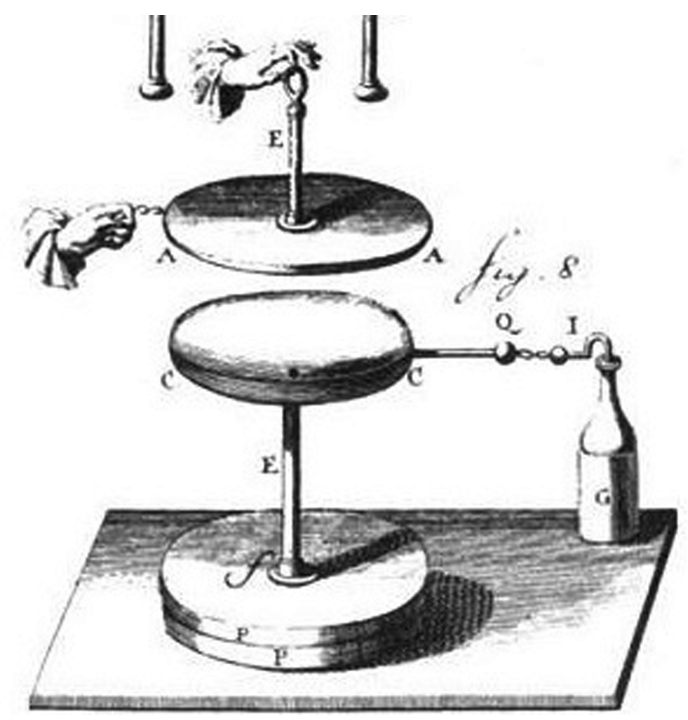

Figura 2: O Eletróforo de Volta carregando uma garrafa de Leiden [39, p.74] O experimentador poderia obter uma quantidade ilimitada de eletricidade a partir do eletróforo simplesmente levantando e abaixando a placa de metal com sua alça isolada, e aterrando e retirando a carga nos momentos apropriados. Com tal aparelho, pode-se carregar qualquer número de Garrafas de Leiden (G) Esta versão do condensador separável efetivamente problematizou as teorias efluviais de eletricidade [40, p. 68].

tar não somente sobre os efeitos observados, mas também sobre a natureza da eletricidade [39,42].

O desenvolvimento do eletróforo, de maneira análoga ao da garrafa de Leiden $[24,42]$, trouxe questões que não foram satisfatoriamente explicadas com o arcabouço teórico do período. Volta, por exemplo, concluiu com base no funcionamento do instrumento que nada "real" (apenas uma espécie de força) poderia passar pelo dielétrico, senão a eletricidade se extinguiria do eletróforo através do isolante. Reflexões acerca do papel dos condutores e isolantes na busca de uma explicação teórica para o eletróforo começaram a suscitar questionamentos sobre a existência ou não de uma eletricidade atmosférica [42]. Em resumo, os estudos acerca da eletricidade atmosférica não davam conta de explicar o eletróforo [40]. Porém, o eletróforo, de maneira similar à Garrafa de Leiden, ampliou a atenção aos estudos sobre eletricidade e, em especial, sobre a eletricidade aplicada a fins medicinais $[38]$.

\subsection{O movimento muscular e a eletricidade}

Outras práticas científicas que se mostram importantes para a compreensão dos processos de construção das ciências iluministas recaem sobre aquelas relativas aos estudos da fisiologia animal e dos movimentos dos músculos. O médico inglês George Fordyce (1736-1802), em uma carta enviada à Royal Society, em novembro de 1787, relata o que podemos chamar de um estado da arte dos estudos relacionados ao movimento muscular naquele contexto [44]. Fordyce, que era professor de medicina e química, além de membro da Royal Society, inicia a carta distinguindo o denominado movimento original (original motion) do movimento comunicado (communicated motion). Esses dois movimentos seriam derivados da alteração do estado de inércia de um corpo, no primeiro caso, por interação de contato com outro corpo e, no segundo caso, decorrente do fato de dois corpos distantes serem trazidos para perto um do outro. Apoiado nessas definições, Fordyce (1788) argumenta que as observações relativas aos movimentos de músculos mostravam que esse tipo de movimento não poderia ser considerado movimento original nem tampouco movimento comunicado [44].

Ele, então, apresentou três teorias, que tinham destaque até aquele momento e que pretendiam descrever as causas do movimento muscular. Embora todas elas considerassem que o agente causador do movimento fosse algo inerente aos animais, o denominado espírito anima $5^{5}$ transmitido do cérebro aos músculos através dos nervos, cada teoria fazia uma análise distinta [44-46]. Uma delas, advinda do século XVII e adotada por diversos estudiosos, considerava que as fibras musculares se contraíam por causa de um processo de fermentação ocorrido pela mistura do espírito animal com o sangue arterial. Outra perspectiva, apoiada no Opticks de Newton e adotada por muitos fisiologistas da Inglaterra, admitia que o movimento muscular era causado por uma vibração etérea através de capilares sólidos, pelúcidos e uniformes dos nervos. A última teoria considerava que o espírito animal era algo similar ao fluido elétrico, sendo transmitido do cérebro para os músculos em grande velocidade [44]. Essa última teoria era bastante aceita entre aqueles que trabalhavam no contexto da "eletricidade medicinal".

Diversos experimentos começaram a ser desenvolvidos com o intuito de analisar a relação entre eletricidade e contração muscular. Johan Gottlob Krüger (1715-1759), em 1745, publicou relatos sobre contrações musculares causadas por um choque elétrico e conclusões de que os efeitos observados em membros normais também os seriam nos membros que sofriam de paralisia [47].

Nesse contexto, a Garrafa de Leiden foi bastante usada. Antoine Louis (1723-1792), fisiologista francês, utilizou a Garrafa de Leiden para investigar uma possível contração em músculos paralisados, mas suas pesquisas apontaram que choques elétricos não causariam movimentos em músculos atrofiados [47]. Jean Jallabert (1712-1767), professor de física da Universidade de Genebra, em 1748, comunicou a manipulação de choques elétricos advindos de Garrafas de Leiden para ativar membros paralisados, investigação essa conduzida e publicada também por Jean Etienne Deshais de Motpellier no ano seguinte. O inglês Benjamin Wilson (1721-1788), em 1750, reportou observações sobre as contrações em músculos "normais". O médico escocês Robert Whytt (1714-1766), em 1751, registrou experiência, na qual observou um retorno de sensibilidade ao braço de um homem que sofria de pa-

\footnotetext{
5 Traduzido do termo original "animal spirit"
} 
ralisia há doze anos, após ter administrado choques regularmente naquele braço. John Shebbeare foi capaz de fazer com que o coração de uma enguia quiescente (Gymnotus electricus) se contraísse por estimulação elétrica e obtivesse contração de forma semelhante a músculos com paralisia recentes. Diversos outros trabalhos que se propuseram a investigar o efeito da eletricidade no movimento muscular foram publicados nos anos seguintes. Nem todos defendiam o movimento dos músculos ser derivado de fluidos elétricos. Por exemplo, outros fisiologistas de renome, como o suíço Albrecht von Haller (1798-1777), argumentavam que os choques elétricos apesar de servirem como estímulos elétricos não podiam ser incontestavelmente considerados como a causa do movimento muscular, afinal, não haveria muito sentido em a eletricidade ser conduzida pelos nervos de maneira a não se espalhar por todos os outros tecidos [46-48].

A existência de uma controvérsia em torno ao que derivava a contração muscular não diminuiu o interesse em relação aos estudos relacionados a eletricidade e contração muscular. No Journal de Médicine, importante periódico de medicina de Paris, entre 1750 e 1780, foram publicados 26 artigos e revisões de obras sobre o tema "eletricidade medicinal" dos quais 12 se destinavam a investigações acerca de choques elétricos para o tratamento de paralisias musculares $[47,49]$.

\subsection{Arraias e Enguias elétricas}

No caminho dos estudos que relacionavam eletricidade ao movimento muscular e outras questões fisiológicas, destacam-se os estudos com enguias e arraias elétricas (torpedos). Havia registro de intensos choques desempenhados pelo contato com os torpedos em textos de Aristóteles, Plínio e Galeno. Durante o Império Romano, eram recomendados choques elétricos advindos de um torpedo para se tratar dores de cabeça e gota. Na Etiópia, a febre era tratada de forma similar $[45,50,51]$.

Em 1666, diversos experimentos acerca das propriedades do torpedo foram desenvolvidos pelo italiano Francesco Redi (1626-1697) na Academia del Cimento. Redi, em sua obra Experimenta Naturalia (1675), descreve em detalhes a sensação do choque recebido ao tocar o torpedo e, em 1678, seu discípulo Stefano Lorenzini (16521700) registrou a dissecação de um torpedo, localizando dois músculos que, quando contraídos, dariam origem a choques que, segundo ele, teriam relação com alguma espécie de eflúvio [51]. Essa hipótese de um eflúvio causador do choque foi trabalhada e modificada no final do século XVII e compôs parte da pesquisa publicada na tese de doutoramento apresentada por Engelbert Kaempfer (1651-1716), em 1769, na faculdade de medicina da Universidade de Leiden. Kaempfer que era médico e naturalista traçou comparações entre o efeito advindo do torpedo com um relâmpago, ou seja, relacionou o fenômeno observado neste animal com os da eletricidade atmosférica $[45,50]$.
Em 1714, Antoine Ferchault de Réaumur (1683-1757), em uma publicação da Academia de Paris, do qual era um dos membros de maior destaque, citou os trabalhos de Giovanni Alfonso Borelli (1608-1679) e Kaempfer para se contrapor à tese de que o choque causado pelo torpedo teria alguma relação com eletricidade. Adotando uma explicação puramente mecânica, ele defendeu que o choque era causado por uma rápida contração dos músculos do peixe, o que gerava um choque mecânico nas pessoas em contato com eles [50]. Para chegar a suas conclusões, ele analisou os trabalhos de diversos estudiosos. Suas conclusões relacionadas a essa explicação mecânica tiveram grande aceitação até a primeira metade do século XVIII [52]. Estudos com arraias e enguias elétricas ganharam destaque no século XVIII, principalmente após o desenvolvimento da Garrafa de Leiden.

É importante ressaltar que o torpedo não foi a única fonte de investigação sobre os choques provenientes de seres vivos. Os primeiros relatos das enguias elétricas datam aproximadamente do início do século XVI a partir de missionários espanhóis em viagem a América do Sul. No entanto, esses missionários não se engajaram em investigações mais sistemáticas sobre as enguias [53].

Na segunda metade do século XVII, relatos sobre as Gymnotus electricus (enguias elétricas) começaram a chegar à Europa a partir de pesquisas conduzidas na América do Sul [50,54]. Por exemplo, Dale Ingram (1710-1793) um cirurgião inglês que enquanto viveu no Suriname, colônia Inglesa e depois colônia holandesa, experimentou os efeitos dessas enguias e as relatou em uma revista de Oxford. Esse artigo foi publicado em inglês e em alemão [53].

Desses relatos, destacam-se muitos advindos dos holandeses sobre as enguias no Suriname. Em meados do século XVII, a Holanda tinha uma produção significativa de estudos com eletricidade e aparatos elétricos e empregava considerável recurso em estudos de zoologia e coleta de novas espécimes, aliado a esses fatores, as enguias eram comuns nos rios da Guiana, onde se estabeleceram diversas colônias holandesas com fins comerciais e estratégicos no período em questão [53].

Nesse contexto, a divulgação desses peixes elétricos alcançou amplo público e novos experimentos foram realizados e novos artefatos construídos. Por exemplo, Henry Cavendish (1776) construiu um aparato com o propósito de ser um torpedo artificial. Na carta enviada à Royal Society e publicada na Philosophical Transactions em 1776, ele descreveu seu aparato (Fig. 3).

A partir da década de 1770, o caráter elétrico dos efeitos observados em arraias e enguias elétricas estava fortemente estabelecido dentre aqueles que se dedicavam aos estudos relacionados a eletricidade advinda de animais [45].

John Walsh (1726-1795), membro da Royal Society e do Parlamento inglês, realizou observações que indicavam ser o choque proveniente dos torpedos, dependentes da vontade do animal e, deduções do médico John Hunter 


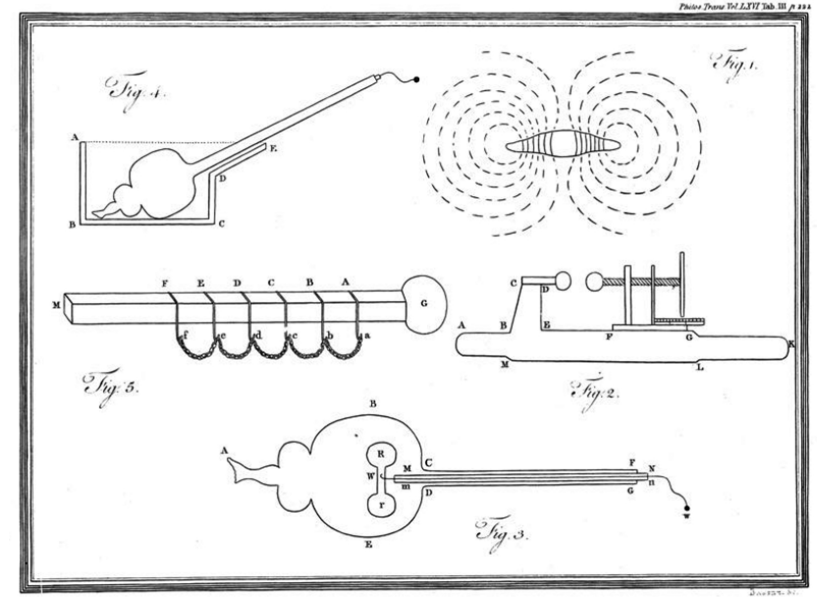

Figura 3: Representação do Torpedo artificial desenvolvido por Henri Cavendish. No lado direito e superior desse desenho, Cavendish representa os caminhos do fluido elétrico através da água de um órgão elétrico ao outro [55,p. 222 e 223].

(1728-1793) indicavam que o poder elétrico estaria intrinsecamente ligado ao funcionamento dos nervos, apontando para a tese de que os fluidos nervosos e o fluido elétrico possuíam uma relação mais próxima. Joseph Priestley seguiu essa linha e se referiu ao trabalho de Walsh, como aquele capaz de demonstrar que "a matéria elétrica, ao estar em um circuito real, passa de uma parte do animal para a outra" [56, p. 275, tradução nossa ${ }^{6}$. Além disso, Priestley afirmou que a presença dessa eletricidade não se limitava àqueles peixes, sendo encontrada em todos os animais e que estes a utilizariam para o propósito da locomoção [56].

Para os fisiologistas inclinados a aceitar o fluido nervoso como sendo de natureza elétrica, a conclusão era direta: as estruturas celulares funcionariam como uma Garrafa de Leiden, extraindo carga dos nervos [46]. Todavia, essa visão não pode ser tomada como unanimidade, pois foi contestada por diversos cientistas $[46,48,16]$. Haller, por exemplo, considerava que o fluido nervoso deveria ter uma natureza distinta de todos os fluidos conhecidos. Isto porque o fluido nervoso deveria ser muito sutil para ser percebido pelos sentidos, mas "mais grosseiro que o fogo, ou éter ou matéria elétrica ou magnética, uma vez que pode ser contida em canais e restringida por ligações e, além disso, é claramente produzida e alimentada por comida" [Haller apud. Foster 1901, [57] p. 297, tradução nossa 7 . A tese de Haller foi aceita por muitos estudiosos, que são denominados hallerianos. A controvérsia acerca do fluido nervoso recaia sobre muitos fatores, enquanto Priestley baseado na química postulava a geração de

\footnotetext{
6 Tradução livre do trecho '[...] the electrical matter which proceeds from it performing a real circuit from one part of the animal to the other $[\ldots] "$

7 Tradução livre do trecho "[...] but more gross than fire, or ether or electric or magnetic matter, since it can be contained in channels and restrained by bonds and moreover is clearly produced out of and nourished by food." (Haller apud Foster, 1901, p.297)
}

eletricidade extraída da comida, Haller em uma visão fisiológica, apontava a impossibilidade do fluido nervoso possuir natureza elétrica justamente pelo fato da comida servir de combustível a ele [45].

\section{Bolonha e o contexto de Galvani}

No contexto dos estudos que envolviam eletricidade e fisiologia, voltaremos nossa atenção a Luigi Galvani, que em 1759 se formou em medicina na Universidade de Bolonha. O ensino oferecido no curso de medicina da Universidade de Bolonha se pautava, em geral, sobre um conhecimento que era tido como obsoleto por muitos que se dedicavam aos novos estudos da área. Nessa e em outras universidades da época, era considerado dever dos professores ensinar o conhecimento estabelecido, não sendo permitido focar nas questões científicas entendidas como em aberto. Considerava-se que ensinar coisas mais atuais confundiria os estudantes, e, portanto, não seria proveitoso. Assim, no intuito de ensinar e investigar novos temas que emergiam naquele contexto, era comum alguns professores ministrarem aulas em suas próprias residências, locais em que eram mais livres para discutir as temáticas desejadas [58]. Apesar de estudar na Universidade de Bolonha apenas as teorias bem estabelecidas, em contato com esses professores, Galvani teve aulas fora dos muros da Universidade e através delas conheceu questões contemporâneas a respeito de fisiologia animal.

Após se formar na Universidade, Galvani continuou a ter contato com muitos desses estudiosos, como foi o caso de Giovanni Antonio Galli (1708-1782). Galvani o acompanhou Galli em práticas cirúrgicas em hospitais locais, o que contribuiu para sua formação prática [58]. O posto de Galli na Universidade de Bolonha passou a ser ocupado por Galvani em 1782 [59].

Galvani estudou ossos, rins, vias urinárias, órgãos e audição dos pássaros e na década de 1770, começou a estudar os músculos, focando na estimulação e paralisia dos mesmos. Ele se utilizou de técnicas antigas, mas também incorporou novas técnicas ou aperfeiçoou algumas das já existentes [48,59]. Nesse caminho, trabalhou com a rã como sujeito de pesquisa e a eletricidade como estimulante. Para ele, experimentos com animais eram fundamentais para se compreender as fisiologias animal e humana [58, 59].

Na divulgação e produção dos estudos de fisiologia, o estudo do corpo humano encontrava seu lugar nos anfiteatros de anatomia, sendo Bolonha, um dos primeiros locais a estabelecer essa tradição, a partir de anfiteatros desmontáveis e, em 1649, com seu primeiro anfiteatro permanente [60]. Nesse contexto, os anfiteatros de anatomia, difundidos pela Europa, eram locais de demonstrações e exibições e que atraiam grande público [10]. Na Holanda, um dos fatores que contribuía para o interesse do público, além dos aspectos científicos, era a existência de fortes crenças religiosas relacionadas a prática de dissecação em cadáveres humanos, que possibilitaria desvelar o trabalho 
magnífico de Deus e a "condição humana" na forma mais visceral. Mas a anatomia carregava implicações que iam além do ressaltado pela teologia e pela ciência, recaindo sobre a hierarquia social e cultural. Existiam banquetes e festividades para comemorar a aquisição de cadáveres, o que reafirmava o status social daqueles que participavam da guilda de cirurgiões. Entre 1603 e 1794, diversos artistas produziram pinturas tendo por cenário as aulas de anatomia, destacando o status social dos participantes da guilda [10].

\section{Os experimentos de Galvani e a eletricidade animal}

No início da década de 1780, Galvani dedicou esforços a desenvolver experimentos que o auxiliassem a investigar a estimulação de nervos e músculos. As técnicas utilizadas estão descritas em sua obra De viribus electricitatis in motu muscularI [61]. Os vários experimentos que conduziu no desenvolvimento desse trabalho receberam auxílio de seu sobrinho Camillo Galvani, que trabalhava no jardim botânico da Universidade e de sua esposa Lucia Galeazzi Galvani (1743-1788), filha de Galeazzi, que frequentemente auxiliava nas pesquisas do marido e na revisão de seus textos $[58,62]$. Lucia recebeu boa instrução em assuntos como história e religião, além de estudar latim e italiano, algo comum para mulheres da alta classe na época em Bolonha. Além disso, ela havia adquirido interesse em ciências e participado de encontros e discussões sobre assuntos relacionados que aconteciam nos Salons de Bolonha, espaço frequentado pela aristocracia da época [62]. Bolonha se destacava pelas muitas learned ladies, mulheres em posição social igual a de Lucia, com formação semelhante e que trabalhavam em laboratórios de parentes $[58,63,64]$. Apesar de, em sua maioria, as learned ladies acabarem por ocupar uma posição periférica na produção científica, dando suporte aos maridos e parentes, encontramos exemplos daquelas que conseguiram construir uma carreira científica pública, tal como a física experimental Laura Bassi (1711-1778), que obteve seu título de doutorado e se tornou professora da Universidade de Bolonha [24,58,62-65].

Assim, com o apoio de sua mulher e de seu sobrinho, Galvani desenvolveu experimentos e destacou ter observado que rãs penduradas em um terraço a céu aberto em grades de metal por ganchos de ferro acoplados às suas medulas espinhais sofriam contração muscular. Essas contrações ocorriam, não apenas durante tempestades, mas também, em condições meteorológicas mais estáveis [Galvani apud [66], p.28-29]. Para explorar esses resultados, ele, como destaca em sua obra, desenvolveu experiências dentro de sua sala (fig.4). Em uma dessas experiências, colocou uma rã em um prato de metal e pressionou um gancho de ferro contra ela, observando contração muscular. Verificou que ao colocar um isolante elétrico entre o nervo e o músculo, a contração não mais ocorria $[48,16]$. Apoiando-se em trabalhos do período, Galvani ar-

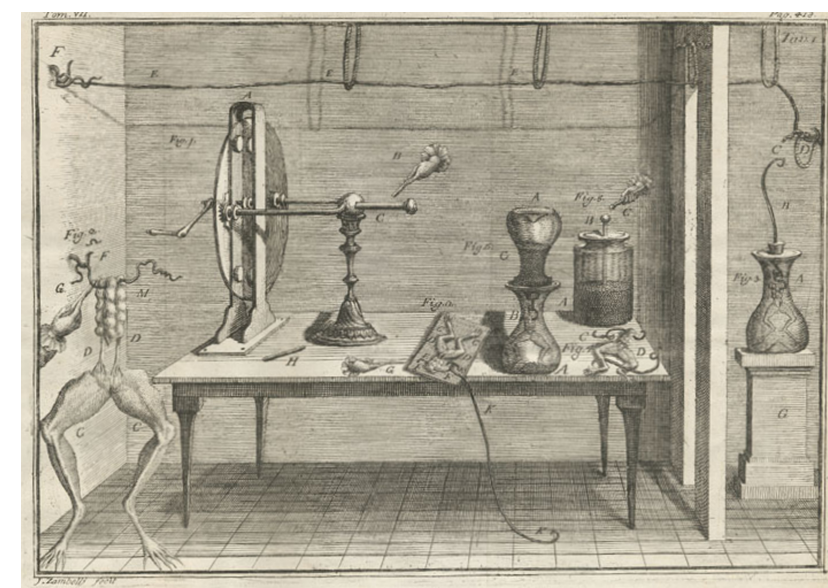

Figura 4: Esquema que ilustra o laboratório de Galvani: Em cima da mesa, a esquerda, a máquina eletrostática [61].

gumentou que, para ocorrer as contrações observadas era necessário produzir uma espécie de desequilíbrio elétrico nos órgãos do animal ou na adjacência dos metais usados. Porém em outubro de 1786, Galvani, em um artigo não publicado, escreveu que seus estudos levavam-no a acreditar que os efeitos observados estariam relacionados aos animais e não aos metais [48]. Os argumentos de Galvani, que apoiavam essa defesa, foram publicados somente 5 anos depois, já com um arcabouço de evidências mais abrangentes. As publicações se deram em formato de artigo (1791) e de livro (De viribus electricitatis in motu musculari commentarius) em 1792 [48].

Em resumo, as principais conclusões apresentadas por Galvani em seu tratado de 1792 apontavam que a contração observada com as rãs ocorria quando um músculo era interligado ao nervo correspondente, através de arcos formados por condutores elétricos e que o efeito era mais forte se esses condutores fossem de materiais distinto 8 sendo que se o nervo estivesse envolto por material metálico, a contração se tornava ainda mais intensa. Análises experimentais de Galvani foram constantemente usadas por ele para sustentar a tese da existência de um fluido animal, diferente da eletricidade ordinária, a denominada eletricidade animal $[40,42]$.

\section{A eletricidade animal e sua repercussão}

Os apontamentos advindos das publicações de Luigi Galvani criaram grande entusiasmo na comunidade científica, pois foram considerados como de grande relevância para a discussão que se travava há décadas acerca da natureza da eletricidade animal (espirito animal). Esse entusiasmo se traduziu em ampla replicação dos experimentos descritos por Galvani [67]. Como eram de fácil replicação,

\footnotetext{
${ }^{8}$ Galvani não diz que o efeito não ocorria se os metais fossem iguais Nas primeiras observações realizadas por ele, foi utilizado ferro e ferro e, em seu tratado, bronze e ferro.
} 
tais experimentos se popularizaram bastante, como ocorreu anos antes com a Garrafa de Leiden, passando a ser apresentados também em sessões públicas de entretenimento, o que levou a uma grande dizimação das rãs na Itália e em seguida, por vários lugares da Europa [67]. A replicação dos experimentos foi realizada por pessoas das mais variadas formações, que passaram a disputar uma explicação para os fenômenos observados, acarretando um grande número de publicações a respeito do assunto em um curto intervalo de tempo $[48,67]$.

A primeira publicação sobre eletricidade animal após os trabalhos de Galvani foi um artigo do italiano Eusebio Valli (1755-1816) de 1792 [67] No livro intitulado Experiments on Animal Electricity with their Application to Physiology and some Pathological and Medical Observations (Experimentos sobre eletricidade animal e suas aplicações em fisiologia e algumas observações médicas e patológicas), o autor destacou as conclusões de Galvani, apontando novas perspectivas de pesquisa [68, prefácio].

Apesar dos trabalhos de Galvani se espalharem rapidamente na Europa, as suas conclusões não foram aceitas por todos. Alguns desacreditaram a proposta de uma eletricidade animal [48]. Por exemplo, Leopoldo Marc Antoine Caldani (1725-1813), ao se referir ao experimento de Galvani, salientou que a contribuição de sua obra decorria apenas em apresentar novas técnicas ou modificações das antigas para o estímulo de contrações animais. Para ele, a obra não continha novidade teórica e empregar as novas técnicas propostas culminaria em um retorno a argumentos já derrubados décadas atrás [67]

Apoiando a perspectiva de Antoine Caldani, seu sobrinho, Floriano Caldani (1772-1836), reconstituiu os experimentos propostos por Galvani e concluiu que apesar de inquestionável a existência de uma eletricidade em corpos vivos, a mesma não teria função fisiológica, sendo apenas um estímulo que saiu da irritabilidade da fibra muscular provocada durante o experimento [67]

Análises dos experimentos com rãs, naquele contexto, dividiam-se em dois grupos. O grupo dos fisiologistas, que consideravam a rã em si como um objeto de estudos e o grupo dos físicos que visualizavam as rãs apenas como instrumentos que tinham por função medir e detectar efeitos elétricos [48,67]. Volta trabalhava nessa segunda perspectiva e, olhando para a rã como um instrumento de medida, em conjunto com o também italiano Bassiano Carminati (1750-1830), desenvolveu um programa de pesquisa que envolveu a comparação dos instrumentos rã e garrafa de Leiden. Os estudos de Volta apontaram para uma nova interpretação dos experimentos apresentados por Galvani, a proposta era que a ação elétrica era gerada a partir do contato dos metais $[67,69]$.

Essa interpretação de Volta foi considerada adequada em diferentes fóruns. Na Royal Society, por exemplo, a qual Volta era um membro e lograva de reconhecimento, os trabalhos de Galvani foram apresentados em 1793 a partir da interpretação desenvolvida por Volta [70].
Esse fato contribui para a construção de uma visão predominantemente antivitalista ${ }^{9}$ naquela academia [71]. A saber, a dinâmica de comunicação do conhecimento científico produzido entre pares influentes desempenhou papel de destaque no período estudado [24,11,72].

No entanto, é importante ressaltar que, as análises de Volta não convenceram a todos [73]. Como exemplos, podemos citar o reconhecido fisiologista Lazzaro Spallanzani (1729-1799) de Pavia, na Itália, que ao tomar conhecimento dos trabalhos de Galvani largou a perspectiva halleriana e adotou aquelas apresentadas pelo anatomista italiano. Além de Spallanzani, diversos outros cientistas associados às cátedras de medicina, física e matemática da Universidade de Pavia se posicionaram a favor de Galvani, ou melhor, do galvanismo, em contrapartida ao que fora proposto por Volta [67].

\section{O contexto de volta em como e Pavia}

Alessandro Volta (1745-1827), nascido em Como, na Itália, era membro de uma família conservadora, advinda da aristocracia Lombarda. Seu pai passou muitos anos junto à comunidade jesuíta e morrera em 1756, enquanto Volta ainda era criança. Após o falecimento de seu pai, Volta, duas irmãs e sua mãe passaram a viver com seu tio. Aos quinze anos, Volta começa a estudar, como interno, em um colégio jesuíta em Como e no ano seguinte, vai para um seminário na mesma cidade. Em contrapartida, nos anos anteriores, Volta fora educado em casa, algo comum naquele período, pelo seu tio, que havia estudado direito e medicina. Além disso, ele provavelmente recebeu instrução educacional de algum dos sacerdotes que eram próximos de sua família [39]. Nesse período Volta se aproximou de conteúdos científicos e literários [39, 43]. Apesar de aparentemente não ter recebido boa formação em matemática e física, que não recebia muita ênfase nas escolas por onde passou, o jovem Volta, por seu interesse, estudou trabalhos científicos, principalmente voltados à eletricidade, como os desenvolvidos por Musschenbroek e Nollet [43].

Em 1765, Volta começou a utilizar o laboratório que Giulio Cessare Gattoni (1741-1809) construiu em sua própria casa. O laboratório contava com ampla gama de equipamentos para uso em pesquisa nas áreas de física, história natural, meteorologia, artes, além de possuir um bom acervo de livros [43]. Gattoni foi o primeiro a construir um pára-raios em Como, em 1768 [39].

Volta começou a se dedicar mais aos estudos de eletricidade em 1769, quando publicou uma carta a Giambatista Beccaria (1716-1781), na qual defendeu que fenômenos elétricos poderiam ser explicados a partir de forças de atração, baseando-se assim numa concepção newtoniana [39]. Importante destacar que um ano antes dessa carta, Beccaria advertira a Volta que ele já havia publicado

\footnotetext{
9 Segundo Mayr [74], o Vitalismo é a Crença, na existência de uma força oculta e invisível nos organismos vivos, responsável pelas manifestações da vida em todo organismo vivo.
} 
um tratado acerca dessa concepção, mas que ao longo de seus estudos abandonara a ideia. Três anos após a publicação de Volta, Beccaria publicou um tratado, no qual apresentou argumentos para, refutar diversas interpretações newtonianas apresentadas por Volta acerca da eletricidade [39].

O engenheiro e matemático italiano, Paolo Frisi (17281784), cuja grande rede de comunicação com a nobreza lombarda lhe garantia recursos e reconhecimento científico, em 1771, aconselhou Volta a empenhar maiores esforços no trabalho com instrumentos e não se embrenhar tão profundamente nas controvérsias teóricas. Para contribuir com esse intuito, ele forneceu a Volta uma tradução para o francês do trabalho de Priestley sobre a história da eletricidade [39]. Apesar dessa advertência, Volta não abandonou por completo as discussões acerca de suas teorias para as propriedades elétricas baseadas na atração. No entanto, Volta se dedicou mais aos instrumentos elétricos e, a partir do trabalho de Priestley tomou conhecimento de aparatos que desconhecia e de questões teóricas relacionadas à eletricidade. A partir da década de 1770, Volta intensificou sua participação na discussão do tema, mantendo encontros com iniciantes, professores de ciências e construtores de instrumentos das escolas de Brera, em Milão [39].

As discussões desenvolvidas por Volta e seus trabalhos de instrumentação, principalmente por desenvolver instrumentos precisos para medir grandezas relacionadas à eletricidade, conquistaram grande reconhecimento e sua rede de comunicação se expandiu bastante [39]. Esses fatores o levaram ao seu primeiro cargo público, em 1774, por indicação de Carlo Firmian (1718-1782), ministro da cidade italiana de Como, que agiu como uma espécie de patrono de Volta nos anos que se seguiram [39,43]. Em 1778, se tornou professor da Universidade de Pavia e ocupou a cadeira de física e física experimental, onde continuou a desenvolver seus trabalhos em instrumentação e eletricidade $[39,43]$.

Após se tornar professor da Universidade de Pavia, Volta, impulsionado por razões científicas, viajou para locais na Europa, como Savoia, Suíça, Alemanha, Bélgica, Holanda, Inglaterra, Alemanha e Áustria. Pretendia com as viagens conhecer novos instrumentos científicos e se aproximar de outros cientistas [43]. A utilização e difusão de instrumentos científicos, e, em especial, aqueles relacionados à eletricidade, estavam muito presentes na Europa no século XVIII. Em 1785, Volta foi nomeado Reitor da Universidade de Pavia.

\section{Alessandro Volta e a eletricidade animal}

Após as publicações de Luigi Galvani acerca dos experimentos com rãs, no início da década de 1790, Volta desenvolveu trabalhos a partir de réplicas desses experimentos e seguiu as conclusões do anatomista italiano ao considerar que os corpos das rãs produziam um tipo especial de eletricidade $[16,45,67]$. No entanto, ao longo da condução dos experimentos com rãs direcionou seu foco para os metais usados no arco condutor, uma vez que o efeito era mais intenso quando os metais a formar o arco eram de materiais diferentes $[45,16,69]$. Em maio de 1793, Volta escreveu uma carta para o italiano Tiberius Cavallo (1749-1809), membro da Royal Society de Londres, na qual afirmou que os efeitos elétricos observados por Galvani não poderiam ter outra causa senão a eletricidade ordinária e que nervos e tecidos teriam apenas um papel passivo de conduzi-la [48,49].

Confrontar essas conclusões com os experimentos realizados gerava um problema, pois, naquele contexto, não havia nenhum aparato (além dos tecidos vivos) capaz de medir pequenas intensidades de efeitos elétricos. Dessa forma, efeitos provenientes das rãs ou de um par metálico isolado dificilmente seriam detectados. Volta se dedicou a esse problema e, em 1796, desenvolveu um condensador (condensatore) sensível aos efeitos de um par metálico $[42,16,75]$. O instrumento consistia em um eletróforo com um isolante fino entre suas duas placas (armaduras). Armadura inferior deveria ser aterrada através do toque de uma pessoa não isolada e, a armadura superior era conectada ao que se queria medir, uma fonte de baixa tensão, como a produzida pelos dois metais diferentes. Dessa forma, separando-se as armaduras, a armadura superior era capaz gerar efeitos passíveis de serem visualizados em um eletrômetro [16].

Com esse instrumento, Volta detectou efeitos elétricos provenientes de pares prata-zinco conectados por um condutor úmido. Ele atribuiu esse efeito elétrico à diferença entre as atrações elétricas produzidas pelos metais [48,75]. A partir dessas informações, alguns historiadores [69,75] inferem que Volta acreditou que a discussão acerca da natureza da "eletricidade animal" chegara ao fim e que suas hipóteses haviam sido comprovadas. Todavia, apesar da reprodução do experimento ser algo simples, e que não exigia grandes perícias técnicas ou conhecimento teórico, replicar alguns dos efeitos relatados por Volta em suas experiências não foi algo simples e muitos pesquisadores não conseguiram obter os mesmos resultados divulgados por ele $[16,72]$.

Com vistas a melhorar as observações pretendidas, Volta se utilizou de vários pares de prata e zinco conectados em série, o que, a princípio, não o levou a maiores efeitos do que os obtidos com um único par. Apesar do aparente insucesso, ele não abandou a ideia de empilhar pares de prata e zinco e, assim, trabalhou em várias possibilidades de empilhamento. Após reformular seus estudos e tomar conhecimento de outros trabalhos sobre instrumentos científicos, tais como os do engenheiro inglês Willian Nicholson (1753-1815), Volta construiu um arranjo que consistia de placas metálicas e condutores não-metálicos de tal forma a unificar o efeito individual de cada par zinco-prata [39]. Nessa perspectiva, ele desenvolveu outro arranjo baseado em copos de água salgada, interligados por condutores metálicos (fig. 5), que, se- 
gundo ele, era capaz de gerar efeitos elétricos, tais como a garrafa de Leiden, porém contínuos [76].

\section{A pilha de Volta e sua repercusão: terminando uma controvérsia?}

Importante destacar, que Volta escolheu a Royal Society para divulgar sua pilha [76]. Essa escolha é compreensível na busca por reconhecimento e difusão de pesquisas acadêmicas naquele período. Naquele contexto, as sociedades e academias tinham um papel crucial no estabelecimento e divulgação do conhecimento científico, e Londres constituía um excelente ponto de partida [11,13,24]. O prestígio dessas academias teve impacto também nos formatos de divulgação do conhecimento, principalmente, no diz respeito às línguas de comunicação, das quais merecem destaque o inglês e o francês, sendo este último o idioma escolhido por Volta para seu anúncio na Royal Society $[11,24,39]$.

Em 20 de março de 1800, Volta enviou para o então presidente da Royal Society, Joseph Banks (1743-1820), uma carta em francês ${ }^{10}$ que seria a primeira das duas

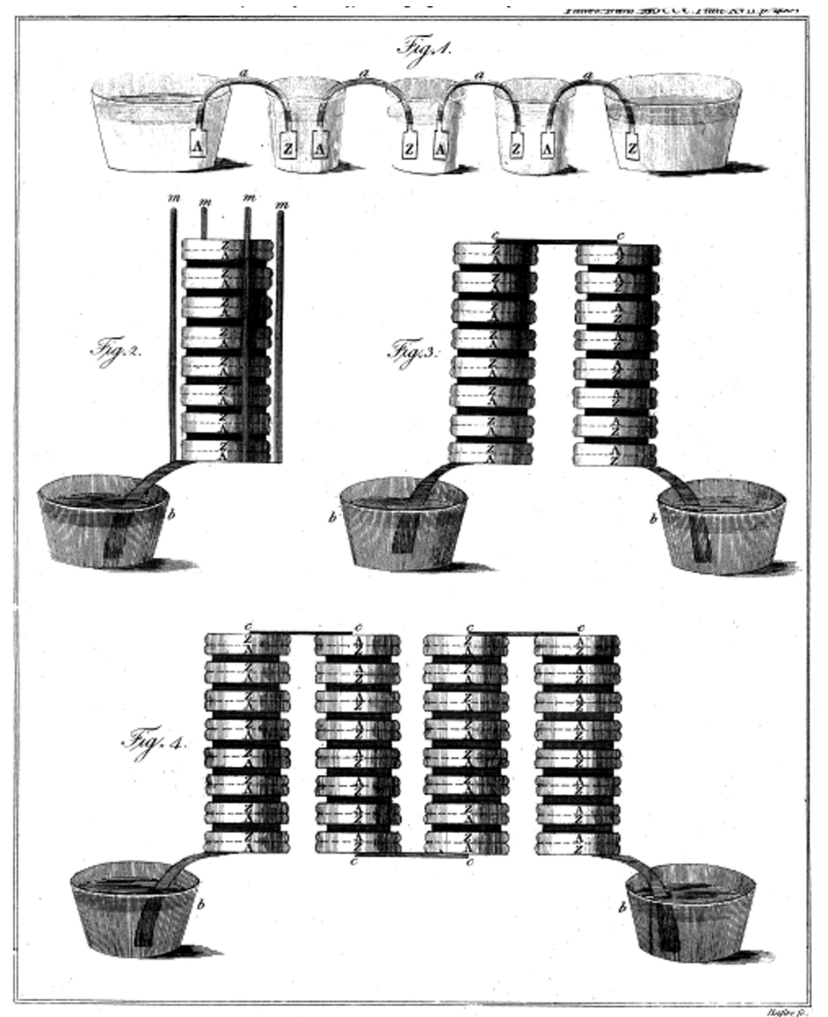

Figura 5: Na parte superior, recipientes com água salgada são conectados por arcos feitos por uma metade de prata e outra de zinco. Em seguida, a versão em coluna da pilha, discos combinados de zinco e prata conectados a outros discos através de papel umidificado. Carta de Volta em 1800 [76].

\footnotetext{
${ }^{10}$ Uma tradução desta carta, para o português pode ser encontrada em $[77]$
}

partes sobre seus estudos iniciais com a bateria, que viria a ser conhecida como pilha de Volta. A segunda carta foi enviada no dia $1^{\circ}$ de abril de 1800 . Enquanto Banks aguardava a segunda carta (que só chegou no dia 3 de Junho) para comunicar oficialmente as investigações de Volta para a Royal Society, ele apresentou os resultados contidos na primeira carta para um pequeno grupo de associados. Dentre esses associados, se encontrava Anthony Carlisle (1768-1840), cirurgião do hospital de Westminster que acompanhado de William Nicholson (1753-1815) começou a conduzir experimentos utilizando o aparato que reproduziram. Wiiliam Nichlson desenvolvia estudos em química e eletricidade além de ser editor do Journal of Natural Philosophy, Chemistry, and the Arts. A partir desses experimentos, produzidos antes da publicação dos trabalhos de Volta, Carlisle e Nicholson observaram um efeito não obtido por Volta, a decomposição da água $[39,72]$.

Apesar de não publicarem seus resultados oficialmente, Carlisle e Nicholson realizaram demonstrações que fizeram com que Thomas Garnett (1766-1802), professor de química, tomasse conhecimento e acabasse por apresentar, em 28 de maio desse mesmo ano (1800), o experimento da eletrólise ${ }^{11}$ da água à Royal Instituiton. A apresentação de Garnett chamou atenção de um jornal de circulação popular, Morning Chronicles, que publicou de maneira breve no dia 30 de maio o experimento de Garnett e uma sucinta descrição do instrumental utilizado para produzir a eletrólise, incluindo a descrição da pilha [39,72]. O Morning Chronicles ofereceu uma breve descrição da pilha (87 palavras foram usadas para descrever a construção da pilha), porém como a estrutura desse artefato era muito simples de ser reproduzida, a mesma foi amplamente replicada e divulgada meses antes da publicação oficial da Royal Society em setembro de 1800 [72].

A pilha de Volta foi largamente acolhida por muitos cientistas e leigos, que se apropriaram do aparato, sem necessariamente discutirem a causa pela qual era gerado o efeito elétrico [72]. A figura 6, indica os principais locais e épocas de divulgação do aparato a partir de Como e Londres.

No artigo de 1800, Volta comparou a pilha com os torpedos e enguias elétricas, concluindo que o aparato possuía as mesmas propriedades da Garrafa de Leiden, apesar de não ser capaz de produzir grandes faíscas ou efeitos eletrostáticos de atração e repulsão. Volta ainda defendeu que seu aparato resolvia o embate em torno à eletricidade animal [16]. Todavia, a pilha não colocou um ponto final na controvérsia, o que não impediu que a mesma continuasse a se difundir rapidamente pela Europa.

A difusão da pilha voltaica foi acompanhada de dúvidas a respeito de seu funcionamento. Por exemplo, a eletricidade gerada por atrito, apresentava efeitos de repulsão e atração, efeito que Volta sem sucesso se em-

\footnotetext{
11 Eletrólise se refere à análise ou decomposição química por meio de corrente elétrica.
} 


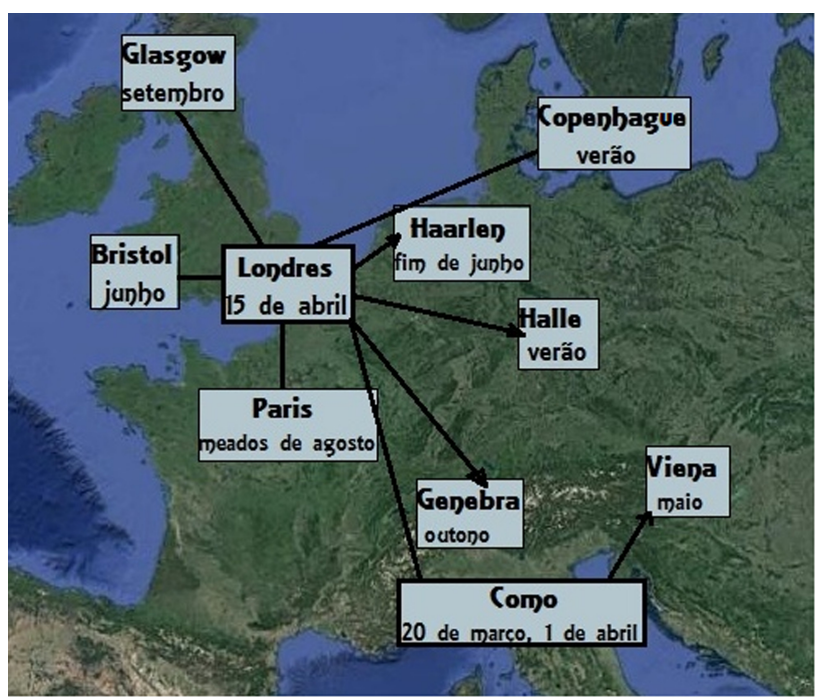

Figura 6: Fluxo das principais comunicações que anunciavam a bateria voltaica, de 20 de março ao outono de 1800 (ilustração feita com base no mapa apresentado por Pancaldi [39, p. 213].

penhou em obter com a pilha. Esse fato gerou dúvidas a respeito da correlação entre a natureza dos efeitos advindos dos estudos galvânicos, dos estudos de Volta e da eletricidade estática [16]. O belga Jean-Baptiste Van Mons (1765-1842), farmacêutico de formação, que desenvolvia pesquisas em química e se comunicava com grandes nomes da ciência naquele contexto tais como Antoine Lavoisier (1743-1794), Antoine François de Fourcroy (1755-1809) e Monge Hachette (1765-1842), em 1801, escreveu uma carta a Volta. Nessa carta, descreveu as impressões que obtivera de Fourcroy acerca da pilha, ou seja, que o fluido gerado pelo aparato, apesar de possuir algumas semelhanças, seria diferente da eletricidade ordinária, pois a pilha não produzia efeitos visíveis sobre eletroscópios nem efeitos químicos, como as pilhas galvânicas [16,78].

Diversos fatores passam, então, a compor a difusão do aparato. Publicações mais acessíveis que a Philosophical Transactions, como a Morning Chronicles ou o Journal of Natural Philosophy, Chemistry, and the Arts, editado por Nicholson, desempenharam um papel importante nessa difusão. Outra publicação de Volta, de 1801, contribuiu com a difusão. Nessa publicação, Volta apresentou uma versão da pilha contida em caixas que, segundo ele, seria voltada para filósofos naturais viajantes [66] Os contatos e a rede de influência de Volta também tiveram importante impacto na divulgação e difusão de seu aparato. Em 6 de novembro de 1801, em Paris, Ferdinando Marescalchi (1754-1816), representante da República Cisalpina na capital francesa, apresentou Volta a Napoleão Bonaparte (1769-1821). Napoleão, que sempre mostrou interesse pela ciência, participou das apresentações científicas realizadas por Volta [39,72].

Naquele contexto, Napoleão buscava ampliar seus poderes pela Europa e reconheceu a representatividade po- lítica de Volta, que era italiano e reconhecido em grande parte da Europa [39], como uma possibilidade interessante para sua legitimidade em território italiano. Em 9 de novembro de 1801, Napoleão recompensou Volta com uma medalha de ouro pela construção da pilha e sua contribuição acerca da controvérsia sobre o galvanismo. A partir daí, o trabalho de Alessandro Volta se tornou ainda mais conhecido e Napoleão utilizou a figura de Volta com propósitos políticos [39].

Vale ressaltar que o interesse de Napoleão pela ciência, exerceu influência direta sobre o que se pesquisou na França e sobre os desdobramentos resultantes do advento da pilha voltaica. A proximidade com a ciência fez com que Napoleão atribuísse funções políticas e financiamentos para diversos cientistas. Se por um lado, alguns cientistas passaram a ter maiores recursos para conduzir suas pesquisas, outros começaram a dispor de menos tempo para se dedicar a tal. Muitas vezes as preferências externadas por Napoleão vinham acompanhadas de vantagens, como no caso dos laplacianos que passam a controlar os principais canais de publicação científica da época, ditando a superioridade do viés defendido pelos mesmos. A intervenção de Napoleão, durante os anos em que esteve no poder, acaba pendendo a balança da controvérsia, na França, para uma visão mais "física" dos efeitos observados a partir da pilha de Volta [78].Um consenso sobre a discussão acerca das causas dos efeitos produzidos pela pilha de Volta não foi alcançado nas primeiras décadas de divulgação do aparato. As explicações para os efeitos da pilha recaiam sobre duas visões principais. A primeira teve como adeptos os que defendiam ser a eletricidade gerada pelo contato entre diferentes metais, Volta se enquadrava nesse grupo, já a segunda, remetia a explicações químicas $[39,69,78,79]$.

\section{Considerações finais}

Esse trabalho teve por objetivo discutir as práticas dos cientistas, em especial as extra-laboratoriais, inerentes ao processo de construção da pilha de Volta, que reconhecemos como de grande potencial para se trabalhar questões sobre a ciência em sala de aula.

O episódio da construção da pilha de Volta permite tecer considerações relevantes sobre a complexidade científica, destacando questões que nos permitem discutir com os estudantes, relações entre ciência, cultura e sociedade. Trabalhar com dissecação de animais e com máquinas elétricas era usual na Europa no século XVIII. Além disso, a manipulação da eletricidade se tornou um assunto muito popular a partir de meados daquele século, podendo ser encontrada em demonstrações de entretenimento, palestras públicas, publicações não acadêmicas e tratamentos medicinais ministrados de forma amadora ou especializada. Instrumentos como as Garrafas de Leiden, geradores elétricos e eletroscópios foram se tornando cada vez mais acessíveis a um público cada vez mais diverso. Nesse contexto, a construção e difusão desse artefato 
ocorreu dentro de controvérsias em torno às explicações dos estudos de eletricidade que se arrastaram por décadas antes e após a construção do mesmo. Estudiosos que se dedicavam as mais diferentes áreas se debruçaram sobre a necessidade de explicar diferentes efeitos produzidos pela eletricidade, construindo, assim, um cenário de grande diversidade de ideias. Trazer essas questões para a sala de aula permite pontuar que estudos sobre a natureza da eletricidade, e, no caso, do fluido elétrico, não foram desenvolvidos exclusivamente pautados em experimentos realizados para esse fim e que os trabalhos desenvolvidos envolveram cientistas de diferentes áreas.

Com as discussões em torno ao desenvolvimento e divulgação da pilha de Volta, podemos ressaltar nas aulas de ciências, que acerca do panorama que compõe as discussões em torno a fisiologia animal e sua relação com a eletricidade, a Itália se apresentou como um dos grandes centros científicos, o que permitia aos cientistas italianos conviver de forma mais intensa com recepção e transmissão do conhecimento produzido naquele contexto. Dessa forma, com esse episódio, podemos destacar com os estudantes que estar em locais e instituições centrais e ter contato com pessoas influentes exerce relação direta com a rapidez das pesquisas desenvolvidas por determinado grupo de cientistas e com a qualidade dos trabalhos desenvolvidos, uma vez que ter participação ativa na rede de produção científica significa conhecer os problemas mais pertinentes e os caminhos já trilhados para respondê-los. Essa discussão pode, assim, permitir trazer questões contemporâneas sobre a ciência, relacionadas, por exemplo, ao impacto que tem o corte ou incentivo de financiamentos em pesquisas científicas para o desenvolvimento dos trabalhos dos cientistas. Nesse ponto, essas discussões podem ser pontuadas com a importância dos financiamentos dados por Napoleão à pesquisa científica naquele contexto.

No desenvolvimento de estudos de eletricidade e de controvérsias em torno à natureza do considerado fluido elétrico, muitos instrumentos e técnicas foram desenvolvidas, ora para responder a alguma dificuldade prática como a necessidade de dosar a quantidade de eletricidade empenhada em um experimento ou tratamento médico, ora suscitando novos questionamentos e possibilidades de investigação, como o caso do eletróforo e da Garrafa de Leiden. Possíveis relações lineares de causa e efeito entre experimento, técnica e teoria se mostram turvas e impossíveis de caber dentro de uma regra simplista e o caso da pilha de Volta é exemplar nesse sentido. Os aparatos e as técnicas desenvolvidas na época se relacionaram diretamente com as pesquisas desenvolvidas naquele contexto e dialogaram com as teorias existentes, apontando novas perspectivas de investigação.

O estudo de questões extra-laboratoriais em torno ao desenvolvimento da pilha de Volta mostra que a experimentação não se impõe como algo invocado apenas para decidir uma disputa, mas como parte integrante da dinâmica de construção do conhecimento científico, como algo que guia e é guiado pela teoria. A construção de um novo aparato ou aplicação de novas técnicas nos casos analisados muito mais contribuíram para intensificar as controvérsias e gerar mais perguntas do que apontar respostas inequívocas, o que é reforçado pelo fato da construção da pilha de Volta não encerrar a controvérsia sobre a eletricidade animal, apesar de ser esse o objetivo de Volta com a construção do artefato.

Outro fator preponderante em nossa análise recai sobre a divulgação do conhecimento debatido. Apesar de terem a Philosophical Transactions da Royal Society e a língua francesa sido escolhidas como vetor para a divulgação inicial do aparato, publicações populares como a do Morning Chronicles de Londres ou publicações acadêmicas mais acessíveis e menos prestigiadas como a do Journal of Natural Philosophy, Chemistry, and the Arts contribuíram para uma prematura e intensa difusão da pilha de Volta instigando não apenas pesquisas acadêmicas, como investigações populares [72]. Em relação ao ensino de ciências, podemos destacar que o acesso ao conhecimento científico por meio das publicações, e os editores dos periódicos foram fundamentais na difusão do aparato e subsequentes nas pesquisas daquele contexto. Todavia, apesar das diferenças e particularidades de cada período, a acessibilidade ao conhecimento, nos dias atuais, continua a ser um fator relevante para o desenvolvimento acadêmico, visto que, ter disponibilizado artigos acadêmicos cujos direitos são detidos por diversos periódicos se atrela diretamente a um custo financeiro sobre o qual nem todos os pesquisadores/instituições podem arcar.

Outro fator importante refere-se a replicabilidade de um experimento. A não replicabilidade suscita questões acerca da validade e estabelecimento de terminado conhecimento, colocando-o, muitas vezes, em dúvida. Uma descrição não detalhada de um experimento ou artefato como a realizada por Ewald Jürgen Von Kleist para a Garrafa de Leiden pode inviabilizar sua reprodução e no caso citado postergou a difusão da mesma, acabando por problematizar a autoria de von Kleist [24]. No caso da pilha de Volta, apesar da sucinta descrição feita pelo Morning Chronicles, a estrutura bastante simples do aparato possibilitou a reprodução em larga escala do mesmo. Era possível, nesse caso, construir o aparato de diversas maneiras, empregando-se materiais e configurações distintas daquelas descritas no artigo, o que gerou diversas variações da pilha e possibilitou que a mesma fosse usada em diferentes contextos [72]. O papel da replicabilidade encontra seu lugar nas discussões relacionadas a validação do conhecimento científico produzido nos mais diferentes contextos. Experimentos como os que conhecemos como Big Science contam com grande rede de colaboradores e estruturas admiráveis. Experimentos conduzidos nos grandes aceleradores de partículas ou nas empreitadas desenvolvidas no LIGO para detecção de ondas gravitacionais tem seu poder de replicabilidade muito restrito, ou muitas vezes, são impossíveis de serem reproduzidos. A realidade trazida por casos como esses não tira valor da 
ciência ali produzida, mas traça parâmetros de validação e análise que devem se adequar ao contexto dinâmico da ciência e, portanto, importantes para tecer discussões sobre as ciências.

Os elementos destacados no presente trabalho não esgotam os fatores que constituem a complexidade por detrás da construção do conhecimento científico presente no desenvolvimento da pilha de Volta. Todavia, acreditamos que a perspectiva de análise a partir das práticas científicas laboratoriais e extra-laboratorias permite levar para a sala de aula discussões sobre a ciência sem apresentações de estruturas que pretendem construir algoritmos gerais sobre como a ciência se constrói e ao mesmo tempo nos afasta de um olhar relativista ao nos aproximar da dinâmica da construção do conhecimento científico nos seus diferentes aspectos.

\section{Agradecimentos}

Agradecemos ao CNPq e a CAPES pelo apoio à pesquisa realizada.

\section{Referências}

[1] T. C. de Mello Forato, M. Pietrocola, R. A. Martins. Caderno Brasileiro de Ensino de Física, 28, n. 1, p. 27-59, 2011.

[2] D. Höttecke, Silva, C. C. Science \& Education 20, 4, 293 (2011).

[3] A. F. Martins, Caderno Brasileiro de Ensino de Física 24, 112 (2007).

[4] P. Galison. How experiments end. (University of Chicago Press, Chicago, 1987), p. 337.

[5] P. Heering, D. Höttecke, in International handbook of research in history, philosophy and science, editado por M. Mathews (Springer Netherlands, Nova York, 2014).

[6] W. T. Jardim, A. Guerra. Investigações em Ensino de Ciências 22, 244 (2017).

[7] J. Pimentel, J. Arbor, 186, 417 (2010).

[8] U. Klein. Experiments, models, paper tools: Cultures of organic chemistry in the nineteenth century (Stanford University Press, Stanford, 2003). p.305.

[9] S. Shapin. American scientist, 77, 554 (1989).

[10] L. Roberts, in The Sciences in Enlightened Europe, editado por Clark, Golinski e Schaffer (Chicago Press, Londres, 1999).

[11] L. Brockliss, In Scholars in Action: The Practice of Knowledge and the Figure of the Savant in the 18th Century, editado por Holenstein, Steinke e Stuber (Ed. BRILL, Boston, 2013).

[12] L. Daston, Science in context, 4, 367 (1991).

[13] J. McClellan III, in The Cambridge History of Science, editado por R. Porter (Cambridge Univestiy Press, Cambridge, 2003).

[14] Burke P. Estudos Avançados, 25, 277, (2011).

[15] M.G. Germano, I. P. C. De Lima, A. P. B. DA Silva. Caderno Brasileiro de Ensino de Física, 29, 145 (2012).

[16] R. A. Martins. Acta Scientiarum, 21, 823 (1999).

[17] C. C. Silva, A. C. Pimentel. Caderno Brasileiro de Ensino de Física, 25, 141, (2008).
[18] S. L. B. Boss, M.P.S. Filho, P. N. L. Filho, J. J. Caluzi, J. R. B. Perez, in Anais do XVIII Simpósio Nacional de Ensino de Física, Vitória, 2009, SBF, 2009. p.1

[19] A. K. T. Assis. Os fundamentos experimentais e históricos da eletricidade. (Apeiron, Montreal, 2010). p. 274

[20] M. S. T. Araújo, M. L. V. S. Abib. Revista Brasileira de Ensino de Fisica, 25, 176 (2003).

[21] A. T. Borges. Novos rumos para o laboratório escolar de ciências.Caderno Brasileiro de Ensino de Física, 19, 291, (2002).

[22] L. Brockliss, in The Cambridge history of science, editado por R. Porter (Cambridge Univestiy Press, Cambridge, 2003).

[23] Holenstein, Steinke, Stuber in Scholars in Action: The Practice of Knowledge and the Figure of the Savant in the 18th Century, editado por Holenstein, Steinke, Stuber (Ed. BRILL, Boston, 2013).

[24] W. T. Jardim, A. Guerra. Caderno Brasileiro de Ensino de Física, 34, 774 (2017).

[25] B. Bensaude-Vincent, C. Blondel, in Science and spectacle in the european enlightenment, editado por Bernadette Bensaude-Vincent, Christine Blondel (Ashgate publishing, Burlington, 2008).

[26] P. Bertucci, in. Curiosity and Wonder from the Renaissance to the Enlightenment, editado por Alexander (Ashgate Publishing, Burlington, 2006).

[27] P. Heering, Science \& Education, 16, 637 (2007).

[28] P. Bertucci. Endeavour, 31, 88 (2007).

[29] P Bertucci. in Science and Spectacle in the European Enlightenment, editado por A B. Bensaude-Vincent e C. Blondel . (Aldershot: Ashgate, Burlington, 2008).

[30] P. Bertucci, In Nuova Voltiana, 5, 31 (2003).

[31] P. Bertucci. in Brain, Mind and Medicine: Essays in Eighteenth-Century Neuroscience, editado por Harry Whitaker, C. U. M. Smith, Stanley Finger (Springer Science \& Business Media, Boston, 2007).

[32] H. BAKER, Philosophical Trans Royal Society 45 (1748).

[33] J. Priestley, The history and present state of electricity, with original experiments. $3^{\mathrm{a}}$ edição (J. Dodsley. J. Johnson,J. Payne and T. Cadell, Londres, 1769). p. 712

[34] W. Watson, Philosophical Transactions 53, 10 (1763).

[35] B. Franklin, Philosophical Transactions Royal Society 50, 481 (1757).

[36] J. Read, R. H. A. Bennet. Philosophical Transactions Royal Society 84, 266 (1794).

[37] T. Lane, Philosophical Transactions Royal Society 57, 451 (1767).

[38] O. Hochadel, In Nuova Voltiana: Studies on Volta and his Times, editado por F. Bevilacqua e L. Fregonese (Universit degli studi di Pavia, Pavia, 2003).

[39] G. Pancaldi. Volta: Science and Culture in the Age of Enlightenment. (Princeton University Press, Princeton, 2005). p.381

[40] T. L. Hankins, Science and the Enlightenment (Cambridge University Press, Cambridge, 1985). p. 226.

[41] A. Volta, in. Scelta di opuscoli interessanti raccolti dalle varie lingue, editado por C. Amoretti e F. Soave (Nella Stamperia di Giuseppe Marelli, Milão, 1775). 
[42] J. L. Heilbron, Electricity in the 17th and 18th centuries: A study of early modern physics (Ed. Dover, Mineola, 1999). p.606.

[43] A. G. Berzolari. In Nuova Voltiana studies on Volta and his time, editado por F. Bevilacqua e L. Fregonese v.1 (2000).

[44] G. Fordyce, Philosophical Transactions Royal Society 78, 23 (1788).

[45] W. C. Walker, Annals of science 2, 84 (1937).

[46] R. Home, Journal of the History of Biology 3, 235 (1970).

[47] H. Hoff, Annals of Science 1, 157 (1936).

[48] N. Kipnis, Annals of science 44, 107 (1987).

[49] A. Mauro, Journal of the history of medicine and allied sciences, 24, 140 (1969).

[50] S. Finger, M. Piccolino, The shocking history of electric fishes: from ancient epochs to the birth of modern neurophysiology (Oxford University Press, Nova York, 2011). p.470

[51] G. Tsoucalas, International maritime health, 652, 65 (2014).

[52] G. M. Jensen, M. E. B Prestes. Philosophy \& History of Biology/Filosofia e História da Biologia, 6, 227(2011).

[53] P.J. Koehler, S. Finger, M. Piccolino Journal of the History of Biology, 42, 715 (2009).

[54] M. Piccolino, M. Bresadola. TRENDS in Neurosciences, 25, 51 (2002).

[55] H. Cavendish, Philosophical Transactions Royal Society 66, 196 (1776).

[56] J. Priestley, Experiments and observations on different kinds of air. (John Adams, Londres, 1775) p. 376

[57] M. Foster, Lectures on the history of physiology during the sixteenth, seventeenth and eighteenth centuries (Cambridge University Press, Cambridge, 1901). p. 320

[58] J. L. Heilbron, Historical studies in the physical and biological sciences, 22, n. 1, 57 (1991).

[59] M. Bresadola, Brain Research Bulletin, 46, n. 5, 367 (1998).

[60] J. Pimentel, in História de Europa, editado por Miguel Artola (org.) (Espasa Libros, Madri, 2007).

[61] L. Galvani, De Viribus Electricitatis in Motu Musculari in De Bononiensi Scientiarum et Artium Instituto atque Academia Commentarii, tomus septimus. (Typographia Instituti Scientiarum, Bolonha, 1791) p.58

[62] M. Piccolino, M. Bresadola, Shocking Frogs: Galvani, Volta, and the Electric Origins of Neuroscience (Oxford University Press, Nova York, 2013) p.376

[63] M. Frize, Laura Bassi and science in 18th century Europe (Heidelberg: Springer, Nova York, 2013). p.196

[64] C. Pal, Republic of Women: Rethinking the Republic of Letters in the Seventeenth Century (Cambridge University Press, Nova York, 2012).p. 320

[65] P. Findlen in The Sciences in Enlightened Europe, editado por Clark, Golinski e Schaffer (Chicago Press, Londres, 1999).

[66] T. Forato, A. Guerra. in Historia da Ciência e Ensino, editado por A. Silva e A. Guerra. (Ed. Livaria da Física, São Paulo, 2015).

[67] W. Bernardi In. Nuova Voltianas, editado por F. Bevilacqua e L. Fregonese (Universit degli studi di Pavia, Pavia, 2000).

[68] E. Valli. Experiments on Animal Electricity with their Application to Physiology and some Pathological and
Medical Observations, (J Johnson St. Paul's ChurchYard, London, 1793). p.352

[69] H. Kragh. Nuova Voltiana, Studies on Volta and his Times, v. 1, 133 (2000).

[70] A. Volta, Philosophical Transactions of the Royal Society of London, 83, 10 (1793).

[71] M. Cavazza, Notes and Records of the Royal Society, v. 56, n. 1, p. 3 (2002).

[72] H. Chang, The transmission of the Voltaic battery. Crossing Oceans. Coleção CLE, v. 75, (2015)

[73] H. SCHIFFER, A. GUERRA. Science \& Education, 24, n. 4, 409 (2015).

[74] E. Mayr. Biologia, ciência única. (Editora Companhia das Letras, Rio de Janeiro, 2005).p.272

[75] J. Mertens, Isis, 89, n. 2, 300 (1998).

[76] A. Volta, Philosophical transactions of the Royal Society of London, 90 403, (1800).

[77] C.P Magnaghi, A.K.T.Assis Caderno Brasileiro de Ensino de Física. 25, n. 1: . 118, (2008).

[78] G. Sutton, Geoffrey. Historical studies in the physical sciences, 11, n. 2, p. 329-366, 1981.

[79] N. Kipnis, In Volta and the History of Electricity. Editado por Kirjassa F. Bevilacqua e E. A Giannetto (Toim. Hoepli. Milano, 2003). 